\title{
La identitat rural com a element d'arrelament i revitalització territorial: primers resultats de la història de vida d'un jove pirinenc
}

\author{
Guillem Riba i Duarte* \\ Laura Domingo Peñafiel $^{* *}$
}

\section{Resum}

En aquest article es presenten els primers resultats de la tesi doctoral 'Identitat Rural: joventut, arrelament i renovació territorial', la qual pretén conèixer i aprofundir en el procés de construcció de la identitat rural de joves originaris d'entorns rurals, que han pres conscientment l'opció d'establir-se en territoris rurals després d'haver passat un període de temps en una àrea urbana. Per fer-ho, s'ha dut a terme prèviament una breu revisió bibliogràfica entorn als conceptes de Ruralitat, Identitat rural i Escola rural. Per tal d'identificar i comprendre els motius pels quals la persona pren l'opció de vida, s'ofereixen les primeres conclusions a partir de la construcció d'una història de vida d'un jove pirinenc català. A grans trets, s'extreu que la identitat rural és un constructe cultural fortament arrelat al territori català, essent un dels potencials factors que afavoreix l'assentament de població. A més a més, la població jove i les escoles rurals en són potencials transmissors, les quals poden afavorir a la dinamització de zones rurals, mitjançant nous models respectuosos amb el patrimoni immaterial i material dins el context històric actual.

\section{Paraules clau}

Identitat rural, ruralitat, història de vida, educació rural, comunitat rural, revitalització territorial.

Recepció original: 21 d'abril de 2020

Acceptació: 27 de juliol de 2020

Publicació: 16 de desembre de 2020

\section{Introducció}

Tal i com exposa Cloke (2006), el món rural és el bressol de coneixement, constructes de pensament, identitat i d'altres components culturals transmesos a partir dels costums i les seves formes de vida. La identitat es conforma a partir del conjunt de característiques pròpies i diferenciades d'un individu o d'un col-lectiu envers d'altres, com també de la relació que estableixen amb el seu entorn i del sentit de pertinença associat. Així doncs, el patrimonicultural es deu al llegat natural i a la interrelació que s'hi manté amb ell. Conseqüentment, la capacitat de les societats per desenvolupar-se de manera sostenible amb el medi i la pròpia cultura, es tradueixen en la seva capacitat de sobreviure.

Des de principis del segle XIX, les fluctuacions demogràfiques de gentrificació cap als nuclis urbans, centres de concentració tecnològica i de serveis, han estat resultat de complexos processos socio-econòmics i culturals com la industrialització, el neoliberalisme i la globalització. La societat catalana, com d'altres de l'òrbita occidental (Cloke, 1987), ha

$\left(^{*}\right)$ Doctorand del programa de doctorat «Innovació i Intervenció Educatives», de la Facultat d'Educació, Traducció i Ciències Humanes (FETCH) a la Universitat de Vic-Universitat Central de Catalunya (UVic-UCC). Mestre d'Educació Primària (Tutor i Llengua Anglesa), a l'Institut Escola Castellterçol. Graduat en Mestre Educació Primària, Menció en Educació Inclusiva i Atenció a la Diversitat (UVic-UCC, 2016). Llicenciat en Periodisme (Universitat Autònoma de Barcelona, 2012).Adreça electrònica: guillem.riba@uvic.cat

${ }^{(* *)}$ Professora investigadora del Departament de Pedagogia de la Facultat d'Educació, Traducció i Ciències Humanes (FETCH) a la UVic-UCC. El seu àmbit d'estudi és l'educació al món rural. Adreça electrònica: laura.domingo@uvic.cat 
menystingut el món rural com a font de coneixement, identitat i de models econòmics sostenibles, perpetuant-lo fins als nostres dies, en qualitat d'àrea per a la producció agropecuària, reserva d'ecosistemes i marc per l'activitat turística. Al seu torn, el mateix món científic (Schmied, 2005) ha tendit a concebre la ruralitat des de patrons de pensament urbans. Així doncs, les àrees rurals s'han definit des d'òrgans de poder intel-lectual i socioeconòmic post-moderns a cavall d'àrees urbanes, nuclis demogràfics i econòmics considerats com a més potents, i a mercè de les polítiques de desenvolupament territorials sovint dissenyades des de les mateixes ciutats i les seves àrees més properes d'influència.

Tot i així, la Fundació del Món Rural (Aldomà i Buixadé, 2015) defensa que l'agricultura, la ramaderia o la silvicultura són activitats econòmiques vinculades i integrades a l'entorn natural i dependents de les seves condicions, sobre les quals recau el manteniment en una relació simbiòtica, àdhuc l'equilibri socioambiental. L'equilibri d'un territori i el benestar dels seus habitants també es vinculen al grau de coneixement de la societat que hi resideix i com actua en conseqüència. La cultura rural és rica en aquests coneixements per l'experiència històrica sobre el territori, una interacció entre allò humà i allò natural que ha marcat els propis valors socials. Per aquest motiu, el valor que adquireix la terra en el sí de la cultura rural catalana transcendeix el seu caràcter productiu, representa les bases que sustenten l'essència de la identitat catalana, d'allò que ens fa ser nosaltres mateixos a partir d'un fort compromís i una aposta de vida pel territori.

El llegat cultural i antropològic (coneixements locals basats en l'experiència i l'observació del medi a llarg termini, els models de vida i comportament, i la cosmovisió) del món rural català pot enriquir l'escola catalana en la pedagogia, la didàctica, l'organització i relació entre actors endògens i exògens, com també a la societat a la qual pertany, atès que comparteix un context sociocultural comú, necessitat de principis i accions educatives respectuoses i sostenibles.

Actualment, les societats occidentals confereixen recursos i esforços en les funcions socioeconòmiques de tots els elements i òrgans educatius i, específicament, en els processos cognitius relatius a la concepció, identificació i reconeixement de fenòmens o realitats on es participa i s'hi està interrelacionat de manera directa o indirecta. Cal focalitzar l'atenció en el fet de donar valor a la identitat rural per tal d'estimular el territori (a nivell socioeconòmic i cultural) i la xarxa de relacions que es dóna en l'entorn rural i de transició a l'urbà (a nivell nacional o macro, però també a nivell micro degut al volum de la comunitat i a la qualitat de les relacions que suposen un fort lligam amb el territori), la qual resulta una diferència marcada amb les de tipus urbà, mitjançant l'educació com a eina de sensibilització i creació d'identitat. Així doncs, aquesta promou en l'àmbit rural la consolidació, I'arrelament i l'alta potencialitat constructiva demogràfica i econòmica, però també en àrees urbanes en permanent interrelació; perquè des de l'àmbit urbà rebi aquest producte amb valor afegit de tipus cultural, cal primer identificar-lo, reconèixerlo i donar-li valor.

Els instruments, recursos, habilitats i competències desenvolupats en els contextos anteriors també poden ser de gran utilitat en l'òrbita occidental actual, especialment en l'urbà, atès que és manifest (en una societat de trets globalitzats en constant extensió) la necessitat de repensar els models educatius que generin principis i relacions segures i respectuoses entre individus i agrupaments socials (com també intersocials) amb el medi on es troben. Àdhuc entendre i estimular la innovació més enllà de l'òrbita urbana, en una concepció del territori més líquida i amb inputs de tot tipus: fluctuacions de persones 
que retornen o arriben a l'entorn rural, noves formes de comunicació, vida i desenvolupament econòmic, entre d'altres.

El present article forma part de la tesi doctoral «ldentitat Rural: joventut, arrelament i renovació» inscrita l'any 2017 al programa de doctorat «Innovació i Intervenció Educatives» de la Facultat d'Educació, Traducció i Ciències Humanes (Universitat de Vic-Universitat Central de Catalunya). Aquest té per objectiu principal identificar els trets que conformen la construcció de la identitat rural en relació a l'establiment en l'àmbit rural per part de joves que han pres aquesta opció de vida de manera conscient. Tanmateix, l'article s'estructura en dos grans apartats. El primer contextualitza i defineix la identitat rural i les bases que la conformen per establir les categories que en permetin el seu estudi, a través de la revisió de fonts bibliogràfiques sobre el tema d'estudi: la identitat rural. També fa una breu anàlisi del paper que desenvolupa l'Escola rural com a ens estimulador de l'assentament territorial i espai de construcció dels trets culturals de la població rural. En el segon apartat s'exposen els trets metodològics principals sobre la investigació qualitativa (història de vida) realitzada sobre un jove pirinenc de la Cerdanya lleidatana, com a cas paradigmàtic de jove rural que ha passat per un procés d'anada i retorn al seu entorn originari. Es pretén explorar de forma completa i contextualitzada els factors de l'entorn (en diversos àmbits: socio-culturals, econòmics, polítics, etc.) que han conformat la seva identitat durant la seva trajectòria vital. Identificar i comprendre els motius pels quals la persona pren l'opció de vida, àdhuc conèixer els motius que van portar a abandonar i, més tard retornar a l'entorn rural (familiars, estudis, laborals, socioambientals) que ajudin a mostrar el nou perfil de la ruralitat a Catalunya; com també identificar els elements i sinergies externes a l'entorn rural que afavoreixen la seva consolidació i desenvolupament del mateix a l'actualitat. Finalment, s'exposen les primeres conclusions derivades de l'anàlisi dels resultats de les entrevistes en profunditat. Aquestes, juntament amb entrevistes amb d'altres agents claus pel subjecte, formen part de la construcció de la història de vida.

Amb tot, cal destacar que el present article s'emmarca dins el treball conjunt de molts agents i projectes de desenvolupament territorial del món rural per incentivar i facilitar el retorn i la inserció laboral dels joves a les zones rurals en equilibri amb els propis trets econòmics, socials i culturals. Alguns d'ells són anònims, d'altres són: Odisseu, Start-up Rural, ENFOCC i I'Escola de Pastors de Catalunya.

Com defensa Boix Tomàs (2002, p. 120), cal «conèixer la seva història, les xarxes econòmiques, les relacions interpersonals, les seves mancances i les seves necessitats, així com també, les opcions de vida de cadascun dels seus habitants» per poder dissenyar polítiques educatives i socials adaptades a les característiques locals (pròpies del territori en la seva diversitat i especificitat) que potenciïn la cohesió i per evitar, amb paraules de la mateixa autora, la injusta exclusió que, durant molt de temps, han patit els seus habitants i que ha influït en aspectes bàsics de la seva vida.

\section{Conceptualitzacions: ruralitat, identitat i educació rural}

Tot seguit, s'ofereix una breu síntesi dels principals fonaments conceptuals que permeten emmarcar teòricament la tesi presentada, amb l'objectiu de conèixer i aprofundir en el procés de construcció de la identitat rural dels joves. Es mostren els conceptes de Ruralitat i d'Escola rural dins el context català, donada la seva transcendència a I'hora de definir, construir i reproduir el concepte i fenomen de la Identitat rural. 


\section{Ruralitat}

Segons exposa Aldomà i Buixadé (2015), el concepte de «ruralitat» és relatiu al de «rural». Emperò, el darrer acostuma a fer referència a aspectes demogràfics, en canvi, el primer serveix per emmarcar una major complexitat, ja que la ruralitat (Trepat i Deltell, 2017) es veu condicionada per factors demogràfics (poca densitat de població), però també d'altres com econòmics (dedicació productiva en relació al territori: sectors terciari i primari), geogràfics (àrees amb poca presència humana i distància en relació a nuclis de serveis i administració), tecnològics i comunicatius (accés a infraestructures i comunicacions endèmicament deficients), socials (proximitat en diferents esferes socials, interdependència en naturalesa de les relacions, reticència a establir confiança amb persones i elements aliens) i culturals (costums, modes de vida, cosmovisió, valors i trets identitaris normalment vinculats directament amb l'entorn, a un llegat tradicional i a poca confiança en els beneficis del canvi).

A l'hora d'establir un llindar de densitat de població per separar les àrees rurals de les urbanes no s'ofereixen valors absoluts per part de la comunitat científica. L'Organització per a la Cooperació i el Desenvolupament Econòmics (OCDE, 2020) diferencia els municipis rurals dels urbans segons si tenen o no una densitat poblacional de 150 habitants per quilòmetre quadrat. En canvi, I'Instituto Nacional de Estadística (INE, 2020) espanyol estableix que els municipis rurals són aquells que tenen una població inferior als 2.000 habitants. Al Principat de Catalunya, els indicadors relatius a les àrees rurals són: el «Mapa de la distribució de la població de Catalunya» de l'Institut Cartogràfic i Geològic de Catalunya (IdesCat, 2019); el «Percentatge de la població resident en disseminats i petits nuclis sobre la població municipal» (essent les comarques amb índex d'entre 25 i 100 les que tenen un major nombre de municipis menors a 2.000 habitants), segons I'ldesCat (2019); el mapa de la «Caracterització de la ruralitat dels municipis a partir dels criteris de densitat i població» (Aldomà i Buixadé, 2015) i el mapa de les «Comarques i els municipis susceptibles de beneficiar-se de les ajudes del programa de Desenvolupament Local Participatiu Leader per als anys 2014-2020» (Aldomà i Buixadé, 2015).

Tot amb tot, autors com Pujades Rúbies i Bayona Carrasco (2016) exposen les característiques i l'evolució del món rural de l'àmbit rural des de l'any 2000 fins a l'actualitat. Pel que fa a la demografia, Catalunya ha viscut fluctuacions de població en el darrer segle, amb afectacions molt accentuades en els municipis petits, les quals s'han degut i es deuen en gran mesura als moviments migratoris (nacionals, estatals i interestatals); la majoria dels quals per raons econòmiques, accés a serveis i de benestar. Des de l'any 2000 fins al 2008 es va experimentar un fort creixement arreu del territori manifest en tot tipus de municipis, degut al creixement econòmic. Emperò, en els darrers deu anys de crisi s'ha experimentat un retrocés, degut al saldo natural negatiu subjacent agreujat pel retorn d'immigrants als seus països d'origen i a les limitacions de recursos i condicions que afavoreixen la natalitat, factors que han afectat especialment als municipis de menys de 1.000 habitants.

Pel que fa a les característiques territorials, la localització geogràfica del municipi marca la seva evolució socio-econòmica i cultural, la qual alhora pot actuar com a focus d'atracció econòmica (turisme rural, immigració residencial i de salut, immigració laboral en el sector primari, etc.). D'altra banda, en l'àmbit demogràfic, la millora de la xarxa d'infraestructures i telecomunicacions ha permès la suburbanització i la mobilitat regular per motius laborals-residencials i, conseqüentment (malgrat tenir un model força centralitzat 
de comunicacions, recursos i serveis) mantenir o recuperar lleument poblacions en àrees amb baixa densitat d'habitants que poden gaudir de nuclis administratius i de serveis comarcals (els quals són grans dinamitzadors de l'economia i la societat rural, assegurantne la seva estabilitat); tot i patir processos d'envelliment i masculinització.

Malgrat l'augment d'àrees agrícoles abandonades i la disminució d'explotacions i treballadors dedicats al sector agropecuari (Trepat i Deltell, 2017) (degut a millores tecnològiques i a dinàmiques de mercat neoliberals i polítiques de concentració), han sorgit tendències més crítiques de consum i turisme (qualitat dels productes i relació respectuosa amb el medi) que han afavorit l'acostament entre productors-consumidors, un retorn a la producció petita o familiar i una voluntat de recuperar formes tradicionals de vida (essent-ne exemple l'Escola de Pastors de Catalunya i l'Associació Rurbans); les quals es nodreixen de parelles joves i la diversitat ocupacional, com també de les polítiques d'inversió i gestió estimuladora del medi rural de l'administració pública (com per exemple les Zones Escolars Rurals, les ZER). Econòmicament, aquests petits municipis acaben essent més dinàmics i repunten en estabilitat, degut a la progressiva diversificació integrada en el territori dels habitants que la poblen (des d'una perspectiva sensible a l'entorn), la qual s'enriqueix amb iniciatives d'emigrants retornats d'origen rural o per neo-rurals d'origen; suggerint una renaixença progressiva de la ruralitat catalana a través de noves formes de relació amb el territori derivades de la crisi on el context rural hi té un nou paper (Nogué, 2016): I'interès, la gestió ambiental i l'economia de caràcter social integrada i equilibrada, col-laborativa i amb autonomia i capacitats d'iniciativa rurals (Aldomà i Buixadé, 2015), com també pel pes de la dona com a agent estimulador de l'activitat i les relacions socioeconòmiques (Trepat i Deltell, 2017). Conseqüentment, l'estabilització i creixement de municipis petits és el primer pas cap a la dignificació del món rural que significa reconèixer la identitat cultural de la societat que viu i vivia en aquell entorn.

El fet que el territori català tingui una superfície rural del 75\% amb una població resident del $10 \%$ sobre el total (IdesCat, 2019) i que sigui on s'origini la identitat del seu poble (Cloke, 2006), malgrat les actuals dinàmiques culturals i socials d'urbanització en el marc de globalització, ofereix un ampli ventall de possibilitats i motius econòmics, ambientals, científics, antropològics i polítics que no haurien de deixar indiferent a les polítiques territorials de la Generalitat de Catalunya ni a cap administració.

Al seu torn, la població jove que retorna, es queda o s'instal.la de nou al món rural contribueix a estimular i diversificar l'economia amb formes actuals d'interconnexió econòmica global (Woods, 2011), ajudant a reactivar i redefinir la ruralitat (Aldomà i Buixadé, 2015), essent un fenomen que no és exclusiu a Catalunya, sinó d'arreu d'Europa que frena la tendència de despoblament rural i, inherentment, també pot influir en la urbanitat pels mateixos motius d'interconnexió i de canvi progressiu en els models i estàndards de consum i d'estil de vida (Nogué, 2016).

\section{Identitat rural}

Segons Cloke (2006) la Identitat rural ha estat definida pels estudis sociològics post-moderns com a un tipus d'identitat territorial, un constructe cultural que respon al reconeixement del sentit de pertinença i a l'autodefinició (Paasi, 2003) modelada a partir de processos de socialització (Haartsen, Groote i Huigen, 2000), valors, constructes i llegat natural i cultural que es donen en entorns rurals els quals han estat i estan en interrelació amb el patrimoni cultural vinculat al territori que genera la ruralitat. D'altra banda, Boix Tomàs 
(2002) i Whatmore (2002) argumenten que és necessari concebre la identitat rural en l'òptica del canvi, en un procés permanent de re-definició a partir de factors socioeconòmics i culturals dins noves formes de comunicació i relació territorials que deixen enrere prejudicis associats a l'ailllament i la marginalitat de l'àmbit rural.

Dins de la Sociologia Rural, Delin i Pospěch (2016) analitzen el procés de construcció de la noció de ruralitat i els múltiples significats atribuïts al medi rural que s'hi associen des d'un enfocament constructivista. Autors com Giddens (1991, p. 187-201) mantenen que les societats es donen i evolucionen en contextos espacio-temporals, els quals modulen les característiques de la pròpia societat i cultura en interrelació amb l'espai físic (Urry, 1985) i amb d'altres societats (Massey, 2005), tot i que segons exposa Rye (2006) el constructe de la ruralitat també depèn de les característiques de classe, gènere, parentiu, localitat, migració i trajectòria vital dels individus que la integren i projecten.

Amb tot, les representacions espaials com la identitat territorial, regional o nacional (Paasi, 2003) exerceixen una forta influència en els grups que interactuen amb elles (Holloway, 2002), afectant-los psicològicament a nivell individual i col-lectiu en processos del seu desenvolupament (Cloke, 2006), suposant models de pensament i codis de conducta diaris o a llarg termini (Holloway, 2002), vinculats amb les representacions espaials on s'han donat, originant sentit de lloc, pertinença o benestar, segons exposen Trigger i Mulcock (2005). A més a més, així com planteja Paniagua (2014), la identitat sorgeix de la interrelació entre categories com valors, referents i expectatives, definició d'un mateix i de l'altri, costums, hàbits, tradicions, afers quotidians, problemes compartits, modes o estils de vida, activitats econòmiques, xarxes de comunicació, etc. Cal afegir, segons Atkinson, Fuller i Painter (2012) i Meurk, Broom, Adams i Sibbritt (2013) que el sentiment de pertinença genera connexions amb l'entorn i la comunitat que poden transmetre's de generació en generació, esdevenint conseqüentment en sentiment d'arrelament (González Rodríguez i Gómez Benito, 2002), el qual influeix en les actituds i opinions sobre l'entorn social i les projeccions laborals i projectes de vida que desencadenen (Díaz Méndez, 2005) en arrelament territorial.

Halfacree (2006) aprofundeix en els valors i pràctiques associades al «Model de l'espai rural», entès com una construcció social en la qual els aspectes materials o físics (el lloc), les pràctiques o formes de vida (la vida quotidiana) i els aspectes imaginats o simbòlics (les representacions) s'interrelacionen dinàmicament per atribuir-li significats. Els aspectes físics són relatius a la proximitat a l'entorn natural i a la major exposició d'elements i fenòmens meteorològics, l'aïllament o distància en relació a nuclis de serveis i administratius, degut a la manca o mal estat d'infraestructures i comunicacions; la poca densitat de població i la dedicació a activitats econòmiques agropecuàries, a la gestió forestal i al turisme. Els elements socials es caracteritzen per la proximitat i interdependència entre els actors d'un mateix territori compartit on acostumen a desenvolupar la seva activitat diària (a nivell intragrupal i intergrupal), com també per la reticència a establir vincles de confiança amb persones i elements aliens a l'entorn social esmentat. Els elements culturals es defineixen per la seva vinculació amb el territori i l'entorn físic (fauna i flora, elements meteorològics, orografia i hidrografia, etc.) com també pel profund coneixement del mateix a nivell local; però també amb el llegat derivat de la relació dels avant-passats amb el mateix entorn que formen part de la cosmovisió i de l'estil de vida dels habitants. Aquest sol expressar-se amb costums, tradicions i modes de vida vinculats directament 
amb l'entorn físic, però també amb valors com el reconeixement de la família, la importància de la celebració de tradicions quotidianes o estacionals, el valor de donar i mantenir la paraula, la serenor o la calma en l'estil de vida, la cooperació amb membres de confiança de grup al qual es pertany, el vincle emocional amb el passat i la poca confiança en els beneficis del canvi, i el reconeixement explícit de la pròpia identitat territorial en relació a l'altri, sovint explicitada pejorativament.

\section{Escola rural}

Autors com Jones (1999) i Massey (2005) mantenen que la identitat rural resideix, es modula i transmet en el grup social de la comunitat educativa rural. Així doncs, segons Stockdale (2006) a part de l'entorn familiar, el grup d'iguals en espais de lleure no-reglats i els diferents espais de participació i interrelació social comunitaris, un dels entorns on els joves construeixen la seva identitat és l'escolar. Aquesta té un conjunt de trets propis que la defineixen com a tal i poden ajudar a comprendre amb més profunditat els aspectes que conformen la identitat dels joves. Altrament, és un espai gestionat per professionals, qui poden fomentar-ne el seu estímul, entenent-la en un marc de desenvolupament territorial integral.

Segons Domingo Peñafiel (2014), s'entén per «escola rural» aquell centre educatiu d'Educació Infantil i/o Primària de titularitat pública que es troba situat en un municipi de menys de 2.000 habitants. Es caracteritza per situar-se en un context rural amb gran valor patrimonial, mantenir forts vincles amb la comunitat local, exercir la funció d'estimulador i dinamitzador socio-cultural, tenir una organització multigrau, com també interacció multinivell de l'alumnat amb docents polivalents que ofereixen atenció personalitzada; suposant així un gran potencial pedagògic, degut a ser dinàmiques, flexibles, complexes i de qualitat (Urgell, 2017).

Des de la Segona República, l'escola rural es concep amb un seguit de trets identitaris que fan que no es pugui construir a imatge de la urbana (Soler i Feu, 2002). Posteriorment, el Secretariat d'Escola Rural (SERC) ha treballat des de 1979 (quan es celebraren les primeres Jornades d'Escola Rural) per la transformació i renovació de l'escola rural, a través del Programa de Suport a l'Escola Rural (1982) i els objectius d'aconseguir una escola rural d'identitat i qualitat (Soler i Feu, 2002). Per assolir-ho, s'ha treballat per descentralitzar serveis i recursos escolars, elaborar polítiques educatives contextualitzades, dotar i renovar equipaments i generar la figura del mestre itinerant, mitjançant l'organització de les escoles en ZER per tal d'obtenir i optimitzar més recursos i treballar de forma coordinada amb centres propers de característiques similars (Domingo Peñafiel, 2014).

Fruit d'aquestes polítiques i de les pròpies característiques i necessitats, l'escola rural catalana es converteix en un model innovador i de referència, com diu Soler (2009, p. 62): «laboratori de pedagogia pràctica i en un camp d'estudi per analitzar els moments, els llocs i les intensitats de la renovació pedagògica a Catalunya». L'escola rural esdevé un important nucli d'interacció quotidiana a nivell social i cultural, degut a l'activitat diària que s'hi duu a terme i a la proximitat entre tots els actors que componen la comunitat local. Per aquest motiu, i degut a les seves dimensions, és una institució que facilita la cohesió, la inclusió dels integrants de la societat local, els quals tenen com a referent institucional el centre educatiu on reunir-se, comunicar-se i organitzar-se (formalment o informalment) per resoldre inquietuds o problemes potencials i desenvolupar activitats per 
al benefici comú i en resposta a les necessitats, mitjançant formes que acostumen a assegurar la participació col-lectiva i l'acció col-laborativa i/o cooperativa amb iniciatives pròpies i/o autogestionades. A més a més, permet l'assentament i reproducció demogràfica en àrees baixament poblades, ja que el centre ha de menester serveis i infraestructures que donen feina i asseguren l'escolarització d'infants, conjuntament amb el fet d'oferir serveis associats a l'activitat lectiva com els de menjadors o activitats escolars en horari laboral, malgrat que no acostumen a ser generosos per l'accentuada manca de recursos econòmics de l'administració pública en els anys posteriors a la crisi (Urgell, 2017). Tanmateix, estimula l'arrelament al territori i el manteniment de la identitat rural de la bressola, ja que permet assegurar els costums, tradicions, model de vida i cosmovisió lligat a la terra per part dels membres de tota la comunitat educativa i d'actors relacionats amb la mateixa (avis, veïns, associacions, etc.), ja sigui amb la seva acció educativa o amb les interaccions socials, culturals i econòmiques que es fan a través dels seus integrants. Així doncs, facilita la permanència de famílies i joves que necessitin escolaritzar els seus fills (Singla, 2017), manté nuclis socio-econòmics arreu del territori, reverteix les tendències demogràfiques actuals d'envelliment i masculinització, aporta població en edat laboral i amb iniciativa per desenvolupar petits negocis i mà d'obra en els sectors primari i terciari, com també ofereix la perspectiva de seguir-ne oferint en generacions posteriors i en la mateixa, ja que l'estabilització i creixement dels nuclis rurals actua com a referent i pol d'atracció per a l'arribada de nova població (persones i empreses), assegurant els serveis i mantenint el dinamisme econòmic i sociocultural. Per conseqüent, l'escola rural permet aturar tendències de concentració demogràfica en nuclis urbans de gran magnitud redistribuint-la en petita mesura i frenant el despoblament i disseminació, fet que també ajuda la sostenibilitat mediambiental, la recuperació de terreny susceptible de ser explotat i el patrimoni material i immaterial resident en àrees rurals.

\section{Apartat metodològic}

En aquest apartat es fa una descripció sobre la perspectiva metodològica escollida, el mètode de recerca i les tècniques emprades i les principals característiques de la mostra.

Fruit de la revisió d'antecedents i de l'estat actual del tema de recerca, sorgeix la hipòtesi inicial que sosté que la identitat rural té un pes fonamental en el fet que els joves rurals escullin conscientment l'opció de vida d'establir-se en entorns rurals, després d'haver passat per entorns urbans; significant un factor de desenvolupament i arrelament de la població en aquest àmbit geogràfic. A més a més, els joves poden deixar l'entorn originari i retornar a ell, de forma integrada i inclosa, gràcies a la permeabilitat de la identitat i al reconeixement de les identitats simultànies que es donen dins la societat occidental.

\section{Perspectiva metodològica}

Tenint en compte les aportacions de Hernández (2011), la recerca es fa des d'un enfocament interpretatiu per dotar-la de significativitat explicativa contextualitzada, en correlació a la finalitat de recerca i a la naturalesa de l'objecte estudiat: comprendre, identificar i interpretar els trets que conformen la construcció de la identitat rural en relació a l'establiment en l'àmbit rural per part d'un jove pirinenc que ha pres aquesta opció de vida de manera conscient.

De la mateixa manera, les tècniques de recerca de caire qualitatives (Díaz Méndez, 2005) permeten interactuar en profunditat amb els subjectes estudiats, tot permetent 
profunditzar en el coneixement del seu llegat vital i històric, la naturalesa de les interrelacions que estableixen amb el context social i físic, el seu sistema de valors, les percepcions que tenen sobre sí mateixos i sobre l'entorn (de manera conscient o inconscient), els factors que afecten el desenvolupament del seu projecte de vida, etc.

\section{Mètode de recerca u recollida de dades}

En aquest estudi, l'experiència i les concepcions de l'individu prenen gran rellevància, ja que s'entén la identitat com a procés psicològic i de socialització, permeable i mutable, en el que les dimensions interdependents col-lectiva i individual interactuen, i de la qual els subjectes en són portadors i modeladors. Segons Vilafranca Manguán (2004, p. 15) «la identitat és un procés narratiu, la nostra identitat és el que podem dir de la nostra experiència de vida, és el que narrem del nostre passat i el que reactualitzem constantment. Així, les anomenades literatures del jo poden ser un bon exemple per esbrinar què és la identitat». Amb tot això, Rivas Flores (2009) exposa que les històries de vida, com a tècnica del mètode biogràfic-narratiu, permeten concebre diferents realitats i objectes d'estudi a partir d'un individu i d'una mateixa perspectiva social. A més a més, Bertaux i Kohli (1984) defensen que les històries de vida ofereixen als investigadors l'oportunitat de centrar-se en múltiples nivells de l'individu i de la vida social d'un subjecte, concebent el present com una història en permanent construcció. Bertaux (1988) també exposa que la història de vida no és un mètode estàndard, ateses les repercussions de la implementació de l'apropament etnogràfic a les qüestions sociològiques. No obstant això, permet tenir en compte antigues teories i categories sociològiques (gènere, classe, envelliment, mobilitat, espais o agents culturals entre altres), alhora que obre camí per contemplar i treballar en nous camps com els processos simbòlics.

Així doncs, la metodologia emprada per assolir l'objectiu d'estudi ha estat la construcció d'una història de vida. Per això, s'utilitzen diferents eines de recollida de dades per complementar les entrevistes en profunditat i aconseguir validesa per triangulació d'informació (Rueda Ortiz, 2004), amb la voluntat d'establir contacte amb el subjecte, però també amb més gent del seu entorn per contrastar la informació recopilada: diari de camp, grups de discussió (mestres, representants d'associacions, periodistes, professors, voluntaris, pedagogs, investigadors i d'altres), anàlisi de documents oficials, entrevistes i d'altres productes culturals com objectes personals, material audiovisual, bibliogràfic, etc.

\section{Mostra}

Com plantegen Soto Arango i Naranjo Patiño (2018), la tria de la mostra permet profunditzar en una anàlisi complexa del cas paradigmàtic escollit. Prèviament, s'ha dut a terme un procés de selecció, mitjançant enquestes i entrevistes amb joves rurals procedents de diferents indrets del Principat de Catalunya, de diferents gèneres, però d'edats compreses entre 18 i 29 anys. Joves que van viure una infantesa en l'àmbit rural, és a dir, que van rebre una escolarització en centres educatius rurals, en comarques considerades rurals per l'Atles de la Nova Ruralitat (Aldomà i Buixadé, 2015), àdhuc que les seves famílies són originàries del mateix territori. Per tal de conèixer els motius pels quals decideixen retornar, aquests joves han viscut un procés en el qual van haver de marxar i han tornat conscientment, prenent l'elecció de vida lligada a l'entorn que els hagués vist créixer. Aquest fet, permet identificar els trets concrets de la identitat rural del subjecte estudiat, com 
també els factors que han influït en la construcció de la mateixa i quin pes específic ha tingut la identitat rural en el fet d'assentar-se en un entorn rural i en la projecció en el mateix del seu projecte de vida. El procés de selecció ha ofert un enriquiment i ampliació de la concepció sobre la Identitat rural en base a trets personals (individuals-socials dels subjectes) amb diverses trajectòries vitals, emperò totes vinculades a la comunitat i a l'espai territorial.

L'anàlisi bibliogràfica sobre els elements i contextos de conformació i modulació de la Identitat rural ha permès establir categories d'indexació i anàlisi: entorn físic, família, escola i comunitat socio-educativa, grups d'amistats, entorns i grups laborals, entorns i grups de participació cultural i política. Aquestes categories han estat factors clau per comprendre els valors, les claus de pensament i comportament durant les diferents etapes i espais vitals (antecedents familiars, infantesa, educació primària, educació secundària, formació superior universitària, desenvolupament del projecte vital i perspectives futures) en relació a la identitat de l'individu.

La tria de la mostra ha estat intencional, feta a partir d'una selecció d'enquestes a cinc joves que complien els requisits de tenir menys de 35 anys, haver nascut a rural i haver retornat com a opció de vida. La mostra finalment es correspon a un individu masculí, de 29 anys d'edat, procedent d'un poble de 30 habitants (19 homes i 11 dones; IdesCat, 2019) de la Cerdanya lleidatana, situat a 1.196 metres d'altitud. El subjecte forma part d'una família agricultora i ramadera del mateix municipi on resideix, dedicada actualment a la pagesia i al turisme. Així mateix, va estudiar els primers anys d'Educació Primària en una escola rural del poble veí, es va matricular en una escola concertada per cursar els estudis de Secundària i es formà com a enginyer industrial a la Universitat Politècnica de Catalunya. Després de rebre una beca i de treballar per un centre de recerca adscrit a la universitat on va realitzar els estudis superiors, va engegar una cooperativa de serveis energètics i telecomunicacions en el municipi d'on és originari.

\section{Història de vida. Resultats inicials}

Finalment, per tal d'identificar i comprendre les raons que han causat i influït en què el subjecte de l'estudi prengués l'opció de vida de retornar i establir-se a l'entorn rural, s'ofereixen els primers resultats a partir de les entrevistes amb el subjecte d'estudi. Tenint en compte que per completar la història de vida també s'exploraran els agents més significatius implicats, aquestes conclusions que es presenten són parcials:

\section{La comunitat educativa rural com a factor conformant, transmissor $i$ assentador de la identitat rural}

La revisió bibliogràfica realitzada ha permès definir, des de la perspectiva dels estudis sociològics rurals post-moderns, la Ruralitat (Trepat i Deltell, 2017) com un concepte que integra transversalment les característiques demogràfiques, econòmiques, geogràfiques, tecnològiques, socials i culturals del territori rural. Aquest concepte es transforma segons Urry (1985) i Massey (2005), atenent les característiques de la societat i la cultura que l'habiten en interrelació amb l'espai físic, com també amb l'esdevenir a nivell macro-social en contacte $a m b$ d'altres societats. 
A més a més, com exposen Martín, Corraliza i Berenguer (2001), l'espai rural determina l'activitat econòmica, els hàbits, i el mode de vida dels seus habitants afectant i resultant un eix aglutinant i vertebrador d'aspectes culturals (Halfacree, 1993) com les pautes de comportament, els valors, els constructes, les representacions culturals i el marc de relacions amb l'entorn social i físic. Com d'altres fenòmens socioculturals, la identitat rural es troba en un procés de canvi o actualització (Halfacree, 1993), degut a la seva condició mutable i a les transformacions tecnològiques que afecten transversalment la societat catalana i el conjunt de les de l'òrbita occidental.

D'altra banda, la Identitat rural, es classifica com un tipus d'identitat territorial i concep segons Cloke (2006) i Passi (2003) com un constructe cultural que integra el sentit de pertinença i l'autodefinició. Paniagua (2014) exposa que la Identitat rural té una naturalesa flexible i es constitueix amb la interacció de processos de socialització i categories com referents, constructes específics, valors, expectatives, definició d'un mateix i de l'altri, costums, hàbits, tradicions, afers quotidians, problemes compartits, modes o estils de vida, activitats econòmiques, xarxes de comunicació i trets propis relatius al llegat natural i cultural de les societats rurals; donant especial èmfasi a l'espai on resideixen i amb el que estan interrelacionats.

Tanmateix, les característiques dels entorns, entesos com a ecosistemes amb elements únics segons la seva localització, exerceixen una importància cabdal en la modulació de la identitat (Urry, 1985), atès que contextualitzen els grups socials que hi resideixen i aquests es vinculen amb una interrelació dinàmica de co-conformació: transformant i gestionant els elements naturals, alhora que definint l'activitat econòmica i el mode de vida dels seus habitants. Aquestes condicions, juntament amb la proximitat entre persones de l'entorn social proper, fan que la comunitat educativa rural sigui un element determinant a l'hora de conformar la identitat rural (Rye, 2011), fent que aquesta sigui un catalitzador potencial de l'arrelament al territori de la seva població.

\section{Joves rurals com a estimuladors de la revitalització territorial}

L'estudi de les categories d'indexació i anàlisi relatives als elements i contextos de conformació de la Identitat rural analitzades han estat útils per comprendre els valors, les claus de pensament i comportament durant el transcurs de la trajectòria vital del subjecte.

En primer lloc, s'ha pogut observar com el jove estudiat té un gran domini de les referències estacionals i de l'entorn natural. Nogensmenys, moltes explicacions del comportament de la població en termes culturals i socio-econòmics els vincula a la interrelació de les sinergies humanes amb l'orografia de l'entorn, àdhuc a les polítiques de desenvolupament vinculades amb els recursos naturals.

En segon Iloc, la noció identitària de l'individu es defineix pel mateix com rural o de pagès, de muntanya i català; en l'ordre d'importància conseqüent. Moltes observacions referents a la identitat pagesa i de muntanya es fonamenten en records emocionants o entranyables d'infantesa, relacionats amb el grup d'amics del poble d'on és originari i amb la família; majoritàriament, sempre vinculats amb situacions contextualitzades dins la llar, dins del poble i en els seus voltants. Aquests dos grups són referents i eixos vertebradors del desenvolupament d'esdeveniments en la seva trajectòria vital durant totes les seves etapes. 
A més a més, els fenòmens lúdico-culturals com festes i tradicions són rememorats i presents en el pensament del jove. Costums i tradicions expressats com a fenòmens que, juntament amb les activitats del dia a dia i el mode de vida, expliquen la idiosincràsia social de la qual n'és conscient i se'n sent orgullosament hereu, tant en fets constructius com en d'altres que no ho són. Aquests fenòmens estan vinculats directament amb l'entorn físic, però també amb valors com el reconeixement de la família, el compromís amb la comunitat i amb la feina ben feta, la perseverança i la determinació, la calma i la serenor, la humilitat, la lleialtat i la mesura de l'expressivitat en les relacions interpersonals. Es destaquen els comentaris relatius al fruir de la tranquil.litat en l'estil de vida vinculat amb l'entorn natural, com el respecte envers la feina i el pensar d'altri, envers l'entorn i el patrimoni són valors sovint mencionats, com també la percepció de reserva o desconfiança envers els canvis en estructures o mecanismes antics, autòctons i d'utilitat vigent, els quals són percebuts com a part del llegat propi i social.

La crítica i l'autocrítica del subjecte acostumen a ser modestes i sornegueres, però troben espai obert quan es presenta el binomi de ruralitat envers urbanitat. La pròpia identitat es reafirma en contraposició a la idiosincràsia i al comportament de les persones de ciutat que observa durant períodes de festa i vacances. Encara més, el jove argumenta la pròpia visió pejorativa envers la població urbana i expressa que és un punt compartit amb la major part de persones que formen part del seu cercle de coneixences.

Resta palès que el pes de la comunitat educativa rural és cabdal a l'hora de construir la pròpia identitat i el projecte vital, concretament dels membres familiars i el grup d'iguals; fent especial èmfasi en el fenomen d'establiment de forts llaços (gairebé familiars) de membres del poble, els quals es bolcaren amb atencions envers al subjecte i als seus companys pel pes de revitalització demogràfica autòctona que suposaren per a la comunitat. El grup d'iguals (o «colla») de l'individu manté el vincle i la presència amb major o menor intensitat durant tots els anys, només distanciant-se parcialment durant l'etapa de formació superior dels seus membres, però revitalitzat quan els mateixos acaben aquest període, atès que es retroben en un espai idèntic o similar al municipi d'on són originaris. No obstant, el subjecte destaca la importància de la intensitat del vincle, sense ser necessari explicitar-lo ni revifar-lo a consciència de forma regular.

La importància de la comunitat socio-econòmica de la família en el poble és per a ell un model de referència de codis i conducta quan el subjecte és infant, el qual resta en un segon pla per grups més flexibles de tipus educatius i lúdics durant l'adolescència i l'etapa de formació universitària. Posteriorment, quan el jove torna de la urbs, passa a formar part de la comunitat socio-econòmica dels seus familiars de ple dret i hi participa, involucrant-se fins al punt de passar a formar part del consell regent de l'ajuntament del municipi.

Segons s'ha pogut observar i ha expressat el mateix subjecte, el sentit polític sobre afers econòmics, socials i culturals creix durant la seva joventut, passant de l'escepticisme, el posicionament des de «les dretes» fins a «les esquerres» progressivament «radicals». En aquest àmbit, el pes del factor nacional roman en un segon ordre, mentre que manifesta la disconformitat amb el model de desenvolupament aplicat al territori rural i de muntanya des dels anys 60 del segle XX fins a l'actualitat, fent-ne una anàlisi profunda i perspicaç. El gran compromís amb el territori el porta a defensar els valors tradicionals i propis, des d'una vessant antropològica, amb la necessitat d'augmentar en autonomia envers la principal zona metropolitana de Catalunya, àdhuc del model econòmic basat 
en el turisme i la producció agrícola. Així proposa la recuperació i enfortiment del cooperativisme, reforçat per l'aplicació de models sostenibles, caracteritzats per un augment del pes de la indústria capdavantera en Investigació i Desenvolupament vinculada a les potencialitats del territori i al Ilegat històric.

Així doncs, es pot concloure que, després de dur a terme les entrevistes en profunditat a un jove ceretà, la comunitat educativa rural és determinant a l'hora de conformar la identitat de la població rural (Meurk, Broom, Adams i Sibbritt, 2013), vinculant-la emocionalment amb l'entorn natural i antròpic. Aquest fet, si es donen unes condicions socioeconòmiques favorables, pot suposar un important factor de revitalització demogràfica $\mathrm{i}$, en el cas dels joves que emigren cap a ciutats per treballar o formar-se, acaba suposant una font de dinamització i enriquiment territorial en aspectes culturals i socio-econòmics. Paral-lelament, cal observar com la mateixa escola rural per sí mateixa actua com a factor de revitalització territorial (Taylor i Yunez Naude, 2000), assegurant la continuïtat demogràfica de la població rural. Fet que permet mantenir la gestió d'àrees isolades i la continuïtat del llegat cultural local de la població en interrelació i co-modulació amb l'entorn durant segles.

\section{Referències}

Aldomà i Buixadé, I. (2015) «Atles de la nova ruralitat. Fundació del Món Rural». Disponible a: http://www.fmr.cat/atles/ [consulta 6 de febrer de 2020].

Atkinson, S.; Fuller, S.; Painter, J. (2012) Well-being and place. London, Routledge.

Bertaux, D.; Kohli, M. (1984) «The Life Story Approach: A Continental View». Annual Review of Sociology, 10, p. 215-237.

Bertaux, D. (1988) «El enfoque biográfico: su validez metodológica, sus potencialidades». Cuadernos de Ciencias Sociales: Historia Oral e Historia de Vida, 18, p. 55-80. Disponible a: http://www.sitiosur.cl/publicaciones/Revista_Proposiciones/PROP-29/ 14BERTAU.DOC [consulta 6 de febrer de 2020].

Boix Tomàs, R. (2002) «Presentació: Educació, Ruralitat i Territori: La construcció d'una identitat pròpia».Temps d'Educació, 26, p. 119-120, Disponible a: https://www.raco.cat/index.php/TempsEducacio/article/view/126343 [consulta 6 de febrer de 2020].

Cloke, P. J. (1987) «Rurality and change: Some cautionary notes». Journal of Rural Studies, 3(1), p. 71-76.

Cloke, P. J. (2006) «Conceptualizing rurality». Handbook of Rural Studies. Londres, Sage, p. 18-28.

Delin, M.; Pospech, P. (2016) «The commodification of the rural and the construction of regional identity». Sociologicky Casopis, 52 (2), p. 209-235.

Díaz Méndez, C. (2005) «Aproximaciones al arraigo y al desarraigo femenino en el medio rural: mujeres jóvenes en busca de una nueva identidad rural». Papers: revista de sociología, 75, p. 63-84.

Domingo Peñafiel, L. (2014) Contribucions pedagògiques de l'escola rural. La inclusió a les aules multigrau: un estudi de cas. Vic, Universitat de Vic-Universitat Central de Catalunya, Facultat d'Educació, Traducció i Ciències Humanes (Tesi doctoral. Directores: Dra. Juana María Sancho Gil i Dra. Núria Simó Gil). Disponible a: http://www.tesisenred.net/handle/10803/283165 [consulta 6 de febrer de 2020]. 
Giddens, A. (1991) Modernity and Self-Identity: Self and Society in the Late Modern Age. Stanford, Stanford University Press.

González Rodríguez, J.; Gómez Benito, C. (2002) Juventud rural 2000. Madrid, Instituto de la Juventud.

Haartsen, T.; Groote, P.; Huigen, P. P. (2000) Claiming rural identities: Dynamics, contexts, policies. Assen, Uitgeverij Van Gorcum.

Halfacree, K. H. (1993) «Locality and social representation: space, discourse and alternative definitions of the rural». Journal of Rural Studies, 9 (1), p. 23-37.

Halfacree, K. H. (2006) «Rural space: constructing a three-fold architecture» a Cloke, P. J.; Marsden, T.; Mooney, P. H. (Eds.) Handbook of rural studies. Londres, Sage, p. 63-90.

Hernández, F. (2011) «¿Qué nos cuentan los jóvenes? Narraciones biográficas sobre las relaciones de los jóvenes con el saber en la escuela secundaria». Esbrina, 8, p. 7-13. Disponible a: http://diposit.ub.edu/dspace/bitstream/2445/18348/8/joves-cuentenfinal3.pdf [accés: 1.2.2020].

Holloway, L. (2002) «Smallholding, hobby-farming, and commercial farming: ethical identities and the production of farming spaces». Environment and Planning A: Economy and Space, 34, p. 2055-2070.

Institut d'Estadística de Catalunya (2019) Anuari estadístic de Catalunya. Generalitat de Catalunya. Disponible a: http://www.idescat.cat/pub/?id=aec [consulta 6 de febrer de 2020].

Instituto Nacional de Estadística de España (2020) Instituto Nacional de Estadística. Disponible a: https://www.ine.es/ [consulta el 6 de febrer de 2020].

Jones, G. (1999) «'The same people in the same places'? Socio-spatial identities and migration in youth». Sociology, 33, p. 1-22.

Martín, R.; Corraliza, J. A.; Berenguer, J. (2001) «Estilo de vida, hábito y medio ambiente». Estudios de Psicología, 22 (1), p. 97-109.

Massey, D. (2005) For Space. London, Sage.

Meurk, C.; Broom, A.; Adams, J.; Sibbritt, D. (2013) «Rurality, mobility, identity: Women's use of complementary and alternative medicine in rural Australia». Health \& Place, 20, p. $75-80$.

Nogué, J. (2016) «El reencuentro con el lugar: nuevas ruralidades, nuevos paisajes y cambio de paradigma». Documents d'Anàlisi Geogràfica, 62 (3), p. 489-502.

OCDE (2020) «National population distribution indicator». Disponible a: 10.1787/7314f74f-en [consulta el 6 de febrer de 2020].

Paasi, A. (2003) «Region and place: Regional identity in question». Progress in Human Geography, 27(4), p. 475-485.

Paniagua, A. (2014) «Rurality, identity and morality in remote rural areas in northern Spain». Journal of Rural Studies, 35, p. 49-58.

Pujades Rúbies, I.; Bayona Carrasco, J. (2016) «L'evolució demogràfica recent dels municipis petits a Catalunya: diversitat de trajectòries». Treballs de la Societat Catalana de Geografia, 81, p. 25-43.

Rivas Flores, J.I. (2009) «Narración, conocimiento y realidad. Un cambio de argumento en la investigación educativa», a Rivas Flores, J.I.; Herrera Pastor, D. (ed.), Voz y educación. La narrativa como enfoque de interpretación de la realidad. Barcelona, Octaedro, p. 1736. 
Rueda Ortiz, R. (2004) «El mètode biogràfic: la tornada al subjecte i a la interacció com centre de procés investigador». Temps d'Educació, 28, p. 55-84. Disponible a: https://www.raco.cat/index.php/TempsEducacio/article/view/126399 [consulta 29 de juny de 2020].

Rye, J. F. (2006) «Rural youths' images of the rural». Journal of Rural Studies, 22 (4), p. 409421.

Rye, J. K. (2011) «Youth migration, rurality and class: a Bourdieusian approach». European Urban and Regional Studies, 18 (2), p. 170-183.

Schmied, D. (2005) Winning and Losing: The Changing Geography of Europe's Rural Areas. Aldershot, Ashgate.

Singla, L. (2017) Escola rural, Ilarga vida al poble!. Surtdecasa.cat. Disponible a: http://surtdecasa.cat/pirineus/familia/escola-rural-pirineus-educacio [consulta el 6 de febrer de 2020].

Soler, J. (2009) La renovació pedagògica durant el Segle XX. La cruilla catalana: dinamismes i tensions. Barcelona, Universitat de Barcelona, Facultat de Pedagogia. Disponible a: http://search.ebscohost.com.biblioremot.uvic.cat/login.aspx?direct=true\&db=edstd $x \& A N=e d s t d x .10803 .2953 \&$ site=eds-live\&scope=site_[consulta el 6 de febrer de 2020].

Soler, J.; Feu J. (2002) «Més enllà de l'escola rural. Cap a un model integrat i integrador de l'educació en el territori». Temps d'Educació, 26, p. 133-156.

Soto Arango, D., Naranjo Patiño, D. (2018) «El método de la historia de vida en educación. Diálogo de saberes y construcción colectiva del conocimiento». Voces De La Educación, 3 (6), p. 142-154. Disponible a: https://www.revista. vocesdelaeducacion .com.mx/index.php/voces/article/view/126 [consulta el 6 de febrer de 2020].

Stockdale, A. (2006) «Migration: Pre-requisite for rural economic regeneration?». Journal of Rural Studies, 22 (3), p. 354-366.

Taylor, J. E.; Yunez Naude, A. (2000) «The returns from schooling in a diversified rural economy». American Journal of Agricultural Economics, 82 (2), p. 287-297.

Trepat i Deltell, E. (2017) Introducció a la ruralitat, a L'Escola al Món Rural, una Perspectiva Internacional. Propostes Didàctiques Multigrau, Interdisciplinàries i Contextualitzades. Vic, Universitat de Vic-Universitat Central de Catalunya (5 ed.).

Trigger, D.; Mulcock, J. (2005) «Forests as spiritually significant places: nature, culture and 'belonging' in Australia». The Australian Journal of Anthropology, 16 (3), p. 306-320.

Urgell, G. (2017) Al Penedès, les escoles rurals es fan grans. Surtdecasa.cat. Disponible a: http://surtdecasa.cat/penedes/familia/les-escoles-rurals-al-penedes-0_[consulta el 6 de febrer de 2020].

Urry, J. (1985) Social relations, space and time. In Social relations and spatial structures. Londres, Palgrave, p. 20-48.

Vilafranca Manguán, I. (2004) Autobiografia, identitat i educació. Temps d'Educació, 28, p. 13-26. Disponible a: https://www.raco.cat/index.php/TempsEducacio/article/view/ 126397 [consulta 29 de juny de 2020].

Whatmore, S. (2002) Hybrid Geographies; Natures, Cultures, Spaces. Londres, Sage.

Woods, M. (2011) Rural. Londres, Routledge. 


\section{La identidad rural como elemento de arraigo i revitalización territorial: primeros resultados de la historia de vida de un joven pirenaico}

Resumen: En este artículo se presentan los primeros resultados de la tesis doctoral «ldentidad Rural: Juventud, arraigo y renovación territorial», la cual pretende conocer y profundizar en el proceso de construcción de la identidad rural de jóvenes originarios de entorno rurales, que han tomado conscientemente la opción de establecerse en territorios rurales después de haber pasado un periodo de tiempo en un área urbana. Para ello, se ha llevado a cabo previamente una breve revisión bibliográfica en torno a los conceptos de Ruralidad, Identidad rural y Escuela rural. Aun así, para identificar y comprender los motivos por los cuales la persona toma la opción de vida, se ofrecen las primeras conclusiones a partir de la construcción de los primeros estadios de la investigación en base a la historia de vida de un joven pirenaico catalán. A grandes rasgos, se concluye que la identidad rural es un constructo cultural fuertemente arraigado en el territorio catalán, siendo uno de los potenciales factores que favorece el asentamiento de población. Además, la población joven y las escuelas rurales son potenciales transmisores, las cuales pueden favorecer la dinamización de zonas rurales, mediante nuevos modelos respetuosos con el patrimonio inmaterial y material dentro del contexto histórico actual.

Palabras clave: Identidad rural, ruralidad, historia de vida, educación rural, comunidad rural, revitalización territorial.

\section{L'identité rurale en tant qu'élément d'ancrage et de revitalisation territoriale: pre- miers résultats de l'histoire de vie d'un jeune garçon des Pyrénées}

Résumé: Cet article présente les premiers résultats de la thèse de doctorat intitulée «ldentité rurale:jeunesse, ancrage et réforme territoriale», qui vise à connaître et à approfondir le processus de construction de l'identité rurale de jeunes originaires d'environnements ruraux, qui ont choisi consciemment l'option de s'établir dans des territoires ruraux après avoir passé une période de temps dans une zone urbaine. Pour ce faire, une bibliographie autour des concepts de « ruralité », d'« identité rurale » et d'« école rurale » a été brièvement passée en revue au préalable. Afin d'identifier et de comprendre les motifs pour lesquels la personne choisit une option de vie, les premières conclusions sont proposées à partir de la construction d'une histoire de vie d'un jeune garçon des Pyrénées catalanes. À grands traits, il en ressort que l'identité rurale est une construction culturelle fortement ancrée dans le territoire catalan et qu'il s'agit de l'un des facteurs potentiels qui favorisent l'établissement de population. En outre, la population jeune et les écoles rurales sont ses transmetteurs potentiels, et elles peuvent favoriser la dynamisation de zones rurales, au moyen de nouveaux modèles respectueux du patrimoine immatériel et matériel au sein du contexte historique actuel.

Mots clés: Identité rurale, ruralité, histoire de vie, éducation rurale, communauté rurale, revitalisation territoriale.

\section{Rural Identity as an element of territorial rooting and revitalization: initial results of the story of a young person from the Pyrenean area}

Abstract: This paper presents the first results of the doctoral thesis «Rural Identity: Youth, Settling and Territorial Revitalization», which aim to identify and analyse the construction of rural identity and its formation process. Particular attention is given to young people from rural areas, who have consciously chosen to settle in rural territories after having spent a period of time in an urban area. A brief bibliographical review was first carried out on the concepts of Rurality, Rural Identity and Rural School. To identify and understand the reasons why people choose this life option, we present the initial results of an in-depth interview study based on the construction of a life story of a young person living in the Catalan Pyrenees. Broadly speaking, it can be seen that rural identity is a cultural construct that is strongly rooted in the Catalan territory and is one of the potential factors that favours the settlement of the population. Moreover, the young population and the rural schools are potential transmitters, which can favour the revitalization of rural areas through new models that respect the intangible and tangible heritage within the current historical context.

Keywords: Rural Identity, Rurality, Life Story, Rural Education, Rural Community, Territorial Revitalization. 